\title{
The Views of Thai Buddhist Monks on a Good Death
}

\author{
Bumpenchit Sangchart $^{1^{*}}$, Suksan Promdee Ngamgam $^{2}$, Rawat Ekwuttiwongsa ${ }^{2}$ And \\ Monthida Sangruangake ${ }^{1}$ \\ ${ }^{1}$ Adult Nursing Department, Faculty of Nursing, Khon Kaen University, Thailand \\ ${ }^{2}$ Division of Nursing, Srinagarind Hospital, Faculty of Medicine, Khon Kaen University, \\ Thailand
}

*Corresponding author, email: bamphenc@kku.ac.th

Received: 22/09/2020; published: 30/09/2020

\begin{abstract}
Background:When Buddhist monks were sick, they had to take care of themselves, or they will be taken care of by other monks. The care may be provided until they recover from the illness or throughout life. The monks who are the caregivers go through near-death and death experiences. The purpose of this phenomenological study was to investigate the meanings of a good death based on the experience of 13 Thai Buddhist monks that providing care for the sick monks until the sick monks passed away. Method:Purposeful sampling was used to select participants who voluntarily participated in the study. In-depth interviews were the main methods of data gathering. Established trustworthiness of a qualitative inquiry based on quality criteria of Lincoln and Guba. The methodological interpretations of Diekelmann and Allen established the thematic analysis of this study. Results:Six main themes and six subthemes of a good death emerged from participants which formed the basis of the findings reported: (a) free from suffering, consisting of 1) death without life's restraints, 2) peaceful death, and 3) death as a sleeping person (but not awake); (b) natural death with good deeds; (c) awareness of death, composed of (1) accepting death, (2) preparation before death, and (3) letting things go; (d) last spirituality becoming a mental charity; (e) resting in peace; and (f) nirvana. Conclusion: The results of the present study could fulfill and extend the meanings of good death to a wider and deeper which are different from the previous studies.
\end{abstract}

Keywords: good death; sick buddhist monks; karma; phenomenology; trustworthiness

Copyright $(2013$ Universitas Ahmad Dahlan. All rights reserved.

\section{Introduction}

Death is a natural and unavoidable subject. However, most people fear death and recognize death as a bad thing, bringing different actions to fight with death, or just to extend the breath and slow down death. This does not help patients to recover from illnesses, and it also causes the patients to suffer by using resuscitation devices and equipment. This is not consistent with the theme of achieving palliative care, which is to facilitate good death for patients with the end-of-life stage $(1,2)$.

A good death is an important concept for end of life care. The main goal of the end of life care is a good death experience of patients and families. The question is what good death is. From overseas studies, some themes related to good death include death during sleep and sudden death (3), maintaining dignity and pride (4) preparing for death (5), not being burden of others $(6,7)$, pain and symptom control $(3,8)$, stopping the unnecessary treatment to prolong life $(7,9-10)$ and spirit $(7)$. According to a study by Miyashita and colleagues (11), the ten themes of good death were found. They were environmental comfort, life completion, dying in a favorite place, maintaining hope and pleasure, independence, physical and psychological comfort, good relationship with medical staff, not being a burden to others, good relationship with family, and being respected as an individual. In Thailand, there were several studies investigating the perspectives from the health care team $(12,13)$, patients $(14,15)$ and patients' relatives $(16)$. The knowledge 
gained from these studies confirmed and reflected good death through the experiences of relevant people from different perspectives. The same focus was on the following three dimensions. The meanings of a good death in the physical dimension are death without suffering, peaceful death and death by natural causes. A good death in the psychological dimension includes death without worry, preparing for death and accepting death. In terms of the relationship dimension, a good death is having good relationships with family members and passing away among the beloved ones.

The themes of good death mentioned above are the perspectives of general people, but the perspectives of religious successors have never been studied. In Thailand, there are around 350,000 Buddhist monks in 40,000 temples. Over $90 \%$ of health personnel and Thais are Theravada Buddhists (17). The Buddhists have a way of life on the principles of Buddhism. All Buddhist activities are related to monks. Monks are both spiritual leaders and healers for Buddhists (18). It can be said that monks have important roles in the Buddhist way of life in religious rituals from birth to death, especially in the near-death stage and death. But even monks cannot avoid illness and death. Especially, if the patient at the end of life stage is a monk, it may make the nursing staff feel uncomfortable because of being unfamiliar with the way of life of a monk. They also do not know the right practices and the ways to respect the monks. They also often expect that the monks will help to lead the mind better than them. In the past, when the monks were sick, they had to take care of themselves or it was the obligation all monks. At the present, although each monk is living independently and has less time to take care of each other when the older monks are sick, they will be taken care of by younger monks or their followers (17). Even when the monks are sick, they still must hold disciplines and practices as prescribed by the Buddha (17), which are limited and different from general people. The monks who take care of the sick monks also must facilitate the sick monks to follow the disciplines both in the hospital and at the temple. Such care may be provided until the sick monks recover from the illness or throughout life $(19,20)$.

The monks who are the caretakers, therefore, go through the experience of caring for the sick monks from the beginning until the end stage of life or death. For these reasons, the authors wanted to know how the monks who care for the sick monks perceive or give the meanings of good death; and what the experiences of the monks who care for the sick monks toward good death are. There are no research studies on Thai Buddhist monks' experience of a good death. Therefore, there is remain a gap of knowledge of good death in the view of monks, that profound phenomena and context cannot be accessed to. As a result, the actual needs of the monks cannot be reached by the nursing practices. Fulfillment of the existing knowledge to cover all dimensions of a good death from the diverse perspectives of the concerned people can make it more complete. The phenomenological study, which is a qualitative research method, is an appropriate way to obtain the clarity of nature and the meaning of experience by interpreting the experience that reflects on the mind of that person (21). The obtained knowledge will lead to the expansion of the knowledge about good death covering all dimensions. It can be used in nursing planning to meet the needs of the sick monks and encourage them to achieve good death, which is consistent with and appropriate for society, culture, beliefs, and Buddhist paths. This study aims to describe the meanings of good death based on the experience of the Thai Buddhist monks who care for the sick Buddhist monks.

\section{Methods}

This qualitative study used Heideggerian hermeneutics phenomenology to guide the development of the research questions that evoked the narrative stories of daily experiences and guided analysis. Heideggerian hermeneutic phenomenological study focuses on understanding the phenomena and the meaning of phenomena through the perspectives of the owners of the experience in order to understand and describe the meanings of a good death as well as the experience of the Buddhist monks caring for the sick Buddhist monks. The participants were selected by a purposive sampling method. They were those experienced in the phenomena being studied and were willing to provide information through the interviewers. In this study, the participants were 13 monks who had experience in caring for the sick monks until the end of life: 8 of them were Dhammayuttika Nikaya monks (61.54\%) and 5 of them were Maha Nikai monks (38.46\%). The youngest 
age was 27 years while the oldest age was 75 years (mean $=50.85, S D=15.21$ ). The shortest length of ordination was 7 years, and the longest length of ordination was 44 years (mean $=17.92, \mathrm{SD}=10.74)$. The shortest duration of caring for the sick monk was 1 month, and the longest duration of caring was 7 years (mean $=25.15, S D=27.90)$. They took care of 1-3 sick monks. For the educational level, 5 monks finished primary school level $(38.46 \%) ; 4$ of them finished secondary schools level $(30.77 \%) ; 1$ of them earned an Associate Degree $(7.69 \%)$ and 3 of them earned a Bachelor's Degree $(23.08 \%)$. In addition, of 12 monks attending Dharma study, 2 of them were dhamma scholars, elementary level $(15.38 \%)$ while 3 of them were dhamma scholars, intermediate level $(23.08 \%)$, and 7 monks were dhamma scholars, advanced level (53.85\%).

The research instruments included the researchers and the data collection instrument. The researchers were important instruments affecting the reliability of the data. The first researcher is a nursing instructor who completed a doctoral degree, has had experience in conducting qualitative research and teaching qualitative research for nearly 20 years. The two researchers have had experience in working in the Monk Ward and trained for conducting qualitative research with the first researcher which was their advisor. The data collection instrument was composed of two parts. The first containing closed questions on demographic characterization data: this included age, the length of ordination, experience in caring for sick monks, the educational level, and experience in Dhamma training, and the second was semi-structured interview guide, with open-ended questions composed by guiding questions such as: tell me about your experience of caring for sick monks who is dying. What is the meaning of good death? What does it mean for you to promote a good death? The monks were requested to explain their lived experiences in their own words. After the participants responded to the above question, more questions were asked to gain wealthier data, such as: Could you clarify this further? What is the meaning of that idea? and Could you please provide me an instance in order to assist us to more suitably comprehend your point of view?

The data were collected as follows: The letter explaining the study and the research consent forms was submitted to the abbot to ask for permission to see the monks who had experience in the phenomena being studied. All the participants were provided with a description of the purposes and the cooperation for the interview and the protection of the participants' rights. When the participants consented to participate in this study, they were invited to determine the convenient time and place for interviews. The researcher employed a face-to-face, semi-structured interview technique, lasting 45-60 minutes, audiotaped interview for data collection. Second researchers conducted all the interviews and terminated when the participants indicated they had no more to share or the saturation of data was reached and including the agreed upon length of time had elapsed. That is, the interpretation of the informants' experience is clear and does not appear to contain new information or meanings.

The data collection and analysis occurred in parallel. Teamwork was used to analyze the data and followed the seven-stage process of Diekelmann and Allen (22), consisting of 7 steps: 1) reading and understanding the texts or messages from the interviews; 2) capturing key issues as indicators for organizing the information system;3) validating and identifying theme; 4) identifying the composite theme; 5) examining and discussing the composite theme; 6 ) making a conclusion from all indexes, categories, and meanings; and 7) presenting the conclusion.

The researchers were the most important tools in collecting data and building trustworthiness of qualitative research. The first researcher is a nursing instructor completing a doctoral degree and has had experience in conducting qualitative research and teaching qualitative research for nursing doctoral students. The two researchers were registered nurses who have had extensive experience in providing care to many end-stage patients for more than 15 years and worked in Monk Ward. They were also trained in conducting qualitative research. The trustworthiness of the present study is supported by four criteria: credibility, dependability, conformability, and transferability (23). To achieve credibility: the data was verified by triangulation (method triangulation), including an indepth interview, non-participant observation and note taking as well as member checks and the selection of experienced informants under the study phenomenon who can describe the experience as much and deep as possible for transferability.To determine data 
dependability: the first researcher checked all of the studying processes, made decisions and agreed with the results in the study without conflicts. To obtain conformability: each researcher independently analyzed the data and had the meeting to check the results and describe the phenomena studied so that it can be checked by the first researcher. Transferability was done by selecting a variety of informants with differences in living area, age, length of ordination, the number of sick monks who were given care and educational level to obtain full and comprehensive information.

Ethical approval was given by the Institutional Review Board of the Ethics Committee in Human Research, Khon Kaen University, Thailand. The participants were informed of ethical principles considered during this study in terms of anonymity, confidentiality of collected data and the right to withdraw from this study at any time without being penalized. Also, permission to audiotape the interviews was obtained. The participants also were provided with the details of the study method and process including the possible need for follow up interviews. All collected data was kept with respect to the principle of confidentiality and anonymity by the researcher and only shared with the research team members for research purposes. Anonymity was preserved through using a coding system instead of their names. During an in-depth interview, participants were free to drain their feelings, and they were comfortable to talk about their feelings experiences.

\section{Results and Discussion}

\subsection{Results}

Six main themes and six subthemes emerged from the analysis that described good death based on the views of Thai Buddhist monks in this present study, as below:

Theme 1. Free from Suffering

A good death which is free from suffering includes 3 subthemes: 1) death without life's restraints, 2) peaceful death, and 3) death as a sleeping person (but not awake). A good death based on this view reflects a view of a good death related to physical symptoms as a result of disease progression and treatment. That is, when the disease progresses to the end stage, most of the patients usually suffer from a variety of conditions such as pain, breathing difficulty, fatigue, relying on ventilators, and inserting medical devices into the body, which are the causes of suffering. So, a good death must be without suffering.

"Being treated with intravenous injection, ventilator insertion or tracheostomy causes suffering and makes patients not able to speak. Some patients' hands are tied to the bed because they try to pull the medical devices out. It seems suffering and not natural." (Id12010818-20)

"Good death is dying without pain and suffering. If it is suffering, it is difficult to be conscious." (Id08010615-17)

"Dying easily is good like not being sick or suffering for a long time. It is good to die like we sleep as we do not have to suffer and cause troubles to others." (Id11010203-07)

Theme 2. Natural Death with Good Deeds

A good death according to this view refers to a natural death, which is the natural law that everything is in the three marks of existence. Each person has a limited and unequal life expectancy depending on the actions taken while living. Creating good Karma throughout the life cycle results in a good death. Therefore, a good death in terms of natural death means death at the right time with accumulated good Karma. So, having good or bad death depends on the outcome of the Karmas of each person.

"Good death is natural death based on life expectancy or being old. It is not sudden death such as dying from accidents or being killed. Death by natural causes is good. Everyone wants to live long without having diseases." (Id10010218-22) 
"Good death allows us not causing troubles with others. Good karmas lead to a good death." (Id01010417-19)

Theme 3. Awareness of Death

Awareness of death consists of 3 subthemes: 1) accepting death, 2) preparation before death, and 3 ) letting things go. This meaning considers death as the truth which is a part of life that cannot be avoided and it can happen all the time. It allows people to accept death, live life carefully and always thinks of death. This will result in preparation before death and handling the unfinished work in order to not being burdened on someone behind. When it comes to accepting and preparing for death, it will make the mind clear and let things go because there is nothing to worry about anymore.

"To have a good death, we have to always think that we will die some days, so we have to live life carefully and accept death. Finally, we will be able to let everything go." (Id08010512-15)

"We have to handle what we worry about, or assign to children or grandchildren so that we can die without worry. If we die with worry, it is not a good death." (Id011010222-26)

"Right, a good death is to die without worry. We have to let things go so that we can rest in peace, not going to the hell but going to heaven instead as we have done good karmas." (Id09010622-24)

Theme 4. Last Spirituality Becoming a Mental Charity

A good death is that the last spirituality becomes a mental charity. It means that the spirituality adheres to Buddha, Dhamma, and Sangha while dying and recalls the merit and good things that have been done all life and tries to make spirituality become mental charity and joy, not a distraction, consciousness and mental peace.

"Good death is that people must have confidence and remember the merits that they themselves have made and believe in Buddha, Dhamma, and Sangha. Because when we are going to die, if we think of the merits that we have been made, it will cause ecstasy, calm and consciousness." (Id04010319-22)

"It can be good death anytime if we prepare for it and have consciousness and peach mind. If we have a peaceful mind, we will have a good death." (Id11010415-18)

Theme 5. Resting in Peace

A good death is resting in peace. This implies that after dying, the death will live in a good place and do not fall into the four abysses: hell, demon, ghost, and beast.

"Good death must be in peace in a paradise and not fall into the four abysses:hell, demon, ghost, and beast. Before dying, people are told to rest in peace and not to suffer from anything." (Id11010408-11)

Theme 6. Nirvana

Nirvana in terms of a good death means death at the end of the passion and free from the cycle of birth and death. It is the best death or the highest level of death. To reach nirvana, going through practices for hundreds of years is needed.

"It is right that good death is nirvana as we do not have to be in the cycle of birth and death. It is a good death in Buddhism." (Id08010624-25)

"Nirvana is the highest level of death that we do not have to rebirth or be in the cycle of birth and death. For some people, it takes a long time to practice to reach nirvana even the Buddha still had to practice for 500 lives, but only 10 last Jatakas have been explained; Vessantara was his last life." (Id12010524-27). 


\subsection{Discussion}

The purpose of this present study was to investigate the meanings of a good death based on the experience of the monks who provided care for sick monks. The study revealed that a good death consisted of six main themes and six subthemes: (a) free from suffering, consisting of 3 subthemes: 1) death without life's restraints 2) peaceful death and 3) death as a sleeping person (but not awake); (b) natural death with good deeds; (c) awareness of death, composed of 3 subthemes 1) accepting death 2) preparation before death and 3 ) letting things go (d) last spirituality becoming a mental charity (e) resting in peace and (f) nirvana. The definitions of a good death in themes 1-4 were consistent with the Institute of Medicine (24), which stated that "good death" is the death without physical and spiritual suffering that can be avoided by relatives, patients, and health personnel. Generally, it should meet the wishes of patients and relatives on the basis of medical, cultural and ethical standards. The National Strategic Plan for End-of-Life Health, B.E. 2557-2559 (25) stated that "good death means the death that patients get relief from both physical and mental suffering adequately". They also received spiritual care based on their faith, religion, and culture. They can also be able to clear everything and express their desire for care in the end stage of life for dying peacefully with the dignity of humanity. However, these meanings do not cover the meanings of death in themes 5 and 6 of this study.

The meaning of a good death based on the first theme, which is death without suffering is consistent with previous studies of good death based on the patients' perception $(14,26)$, family members $(16,27)$ nurses and health care team $(12,13,28)$ caregivers who are relatives or family members $(1,29)$. It was found that a good death is death without suffering and not using respirators to prolong life. Giving this meaning describe how patients in the last stage of life suffer from various symptoms such as pain and breathing difficulty. Such symptoms cause suffering to the patients. In addition, some patients have to be treated by using ventilator and inserting medical devices. The monks providing care recognized that this caused the suffering of the patients (13).

A good death is a natural death with good deeds. In Buddhism, there are two types of death: natural death or death based on life expectancy, which is good death and unnatural death such as death from accidents or being killed, which is bad death (30). This also includes death from making some mischief like killing animals causing short-lived. However, making good Karmas affects the after-death stage that leads the dead people to the good new order (31). Natural death based on life expectancy with good deeds in this study is different from previous studies. That is, natural death based on the views of general people is breathlessness without rescuing or prolonging life, or death without penetrating, operating or inserting with medical equipment. On the contrary, natural death based on the views of monks refers to the death of life through the process of every stage of the life from birth to death and the death based on the end of life. There is also a difference in the issue of creating good Karma while living leading to a good death.

The next theme is awareness of death, which is based on the Buddhist doctrine of the three marks of existence or the law of nature that no one can avoid it. Understanding the nature of death allows people to accept death and let go of everything, even their own self. Both physical and mental aspects are prepared before death (32-34). It is a good death. This is different from previous studies. That is, in the views of the monks, the focus of the rule of the three marks of existence is to understand death and be prepared before dying. Preparing for death for the monks are preparing the Dhamma preparation while general people focus on physical preparation such as property management, saying goodbye or ask for forgiveness from others.

Another two themes of a good death are last spirituality becoming a mental charity and resting in peace. According to the doctrine of Buddhism, a good death is death with fine spirituality which will lead to a peaceful place after death or not falling into the four abysses. But, if spirituality is not bright or fine, it will lead to a bad place (32-34). A good death based on this meaning is different from the previous studies which focused only on thinking of merits that have been done and concentrating on the calm and not to be distracted which is the basic meditation. But, based on the monks' views, it is giving, strictly observing the precepts and making meditation and prayer. Prayer makes mental calm and focuses on advanced concentration to have the wisdom to understand the reality 
of life which is the three marks of existence (Impermanence (anicca), Unsatisfactoriness or "dis-ease" (dukkha) and Insubstantiality or "not-self" (anatta). It is letting everything go even body. Letting go can lead to peace.

The last theme is nirvana. Nirvana is peace, the "other shore" from samsara. According to Buddhist doctrine, nirvana is a condition where passion is gone. This is called the Buddhist saint (32-34). Nirvana is the highest goal in Buddhism. Strictly committed to practice is a way to get out of the transmigration of the soul or to achieve the nirvana $(33,35)$. Good death based on this theme has not been found in the previous studies.

\section{Conclusion}

From the experiences of the monks providing care to the sick monks, the meanings of a good death are given in the ways that are both consistent and very different from the meanings of a good death from other previous studies. In terms of the consistency of the terminology, even it is similar but there are still significant differences based on the doctrines of religion such as in themes 2-3. However, it is different in themes 4-6, especially theme 6 which is completely different. The study recommends that 1) Nurses should assess the needs for the death of all monks with the end stage of life to plan the nursing practices in accordance with the needs of the monk and enhance good death. 2) Good death according to the monks' views is related and linked to the doctrines in Buddhism. So, to promote good death in the monks, nursing personnel who provide care for monks should study the basic disciplines of Buddhism. 3) The administrators should provide training on doctrines and disciplines of Buddhism to the health personnel who provide care for monks. 4) The study to create a tool to assess the needs of a good death in the monks with the end stage of life using the data from the research as the basic information should be conducted. In addition, the study of a good death based on the experiences of the monks who provide care for the sick monks in other contexts should also be conducted.

\section{References}

1. KA Kehl. Moving toward peace: an analysis of the concept of a good death. Am. J. Hosp. Palliat. Care 2006; 23, 277-86.

2. T Watts. End-of-life care pathways as tools to promote and support a good death: a critical commentary. Eur. J. Cancer Care (Engl) 2012; 21, 20-30.

3. T Hughes, M Schumacher, JM Jacobs-Lawson and $S$ Arnold. Confronting death: perceptions of a good death in adults with lung cancer. Am. J. Hosp. Palliat. Care 2008; 25, 39-44.

4. K Hirai, M Miyashita, T Morita, M Sanjo and Y Uchitomi. Good death in Japanese cancer care: a qualitative study. J. Pain Symptom Manage. 2006; 31,140-7.

5. KE Steinhauser, NA Christakis, EC Clipp, M McNeilly, L McIntyre and JA Tulsky. Factors considered important at the end of life by patients, family, physicians, and other care providers. JAMA. 2000; 284, 2476-82.

6. JM Teno, VA Casey, LC Welch and S Edgman-Levitan. Patient- focused, family-centered end-of-life medical care: views of the guidelines and bereaved family members. J. Pain Symptom Manage. 2001; 22, 738-5.

7. E Tong, SA McGraw, E Dobihal, R Baggish, E Cherlin and EH Bradley. What is a good death? Minority and non-minority perspectives. J. Palliat. Care 2003; 19, 168-75.

8. JD De Jong and LE Clarke. What is a good death? Stories from palliative care. J. Palliat. Care 2009; 25, 61-7.

9. PA Singer, DK Martin and M Kelner. Quality end of-life care: Patients' perspectives. JAMA. 1999; 281, 163-8.

10. M Miyashita, $T$ Morita, $K$ Sato, $K$ Hirai, $Y$ Shima and $Y$ Uchitomi. Factors contributing to evaluation of a good death from the bereaved family member's perspective. Psychooncology. 2008a; 17, 612-20.

11. M Miyashita, T Morita, K Sato, K Hirai, Y Shima and Y Uchitomi. Good death inventory: a measure for evaluating good death from the bereaved family member's perspective. J. Pain Symptom Manage. 2008b; 35, 486-98.

12. S Piyawattanapong. 2009, Development of palliative care for person with terminal cancer in tertiarycare hospital, Ph. D. Dissertation. Khon Kaen University, Khon Kaen, Thailand. 
13. Y Jompaeng and B Sangchart. Nurses' perception of good death: A phenomenology study. Journal of Nursing Science and Health (in Thai), Khon Kaen University, Khon Kaen, 2013; $36,49-59$.

14. W Khoonsongkiat. Patients' perceptions of good death. Journal of Nursing Science (in Thai), Burapha University, Chonburi, 2001; 19, 1-12.

15. J Rodpal. 2006, Good death: perspectives from Thai Buddhist elderly, Master Degree. Chulalongkorn University, Bangkok, Thailand.

16. $P$ Mapong and B Sangchart. Evaluation of palliative care in critically ill patient: family members' perspectives. Journal of Nursing Science and Health (in Thai), Khon Kaen University, Khon Kaen, 2013; 36, 17-35.

17. W Thammachitto, Phra. Caring for monks in the hospital. Available at: https://www.nationalhealth.or.th/sites/default/files/upload_files/Care_for_sick_monks.pdf, accessed July 2018.

18. T Nakata. Buddhism and Thai society (in Thai). $2^{\text {nd }}$ ed. Sahai Block \& Printing Ltd. Bangkok, 2000.

19. S Ragkhanto, A Khongkhuntod and S Kanchana. Self-care behavior of monks in the upper southern region (inThai). Mahachulalongkornrajavidyalaya University, Surat Thani, 2008.

20. D Buathed. 2010, Buddhist monks' health: a model of holistic health care by community participation in upper central Thailand, Ph. D. dissertation. Mahasarakham University, Maha Sarakham, Thailand.

21. M Van Manen. Researching lived experience: Human science for an action sensitive pedagogy. State University of New York Press, Albany, New York, 1990.

22. N Diekelmann and D Allen. A hermeneutic analysis of the NLN criteria for the appraisal of baccalaureate programs. In Diekelmann N, Allen D and Tanner C (eds.). The NLN criteria for the appraisal of baccalaureate programs: A critical hermeneutic analysis. National League for Nursing, New York, 1989, p. 11-31.

23. YS Lincoln and EG Guba. Naturalistic inquiry. Sage publications, Newbury park, California, 1985.

24. EJ Emanuel and LL Emanuel. The promise of a good death. Lancet. 1998; 351(suppl. II), 21-9.

25. National Health Commission Office. National strategic plan on health promotion at the end of life, 2014-2015(in Thai). $2^{\text {nd }}$ ed. Sam-dee Printing Equipment Company Limited, Bangkok, 2014.

26. T Akechi, M Miyashita, T Morita, T Okuyama, M Sakamoto, R Sagawa and Y Uchitomi. Good death in elderly adults with cancer in Japan based on perspectives of the general population. J. Am. Geriatr. Soc. 2012; 60, 271-6.

27. S Iranmanesh, H Hosseini and M Esmaili. Evaluating the "good death" concept from Iranian bereaved family members' perspective. J. Support Oncol. 2011; 9, 59-63.

28. C Griggs. Community nurses' perceptions of a good death: A qualitative exploratory study. Int. J. Palliat. Nurs. 2010; 16, 140-9.

29. C Granda-Cameron and A Houldin. Concept analysis of good death in terminally ill patients. Am. J. Hosp. Palliat. Care 2012; 29, 632-9.

30. T Kerdkaew. Buddhist philosophy: perspectives of realistic world and life (in Thai). Commercial Word Media, Samutprakarn, 2010.

31. R Exwuttiwongsa and B Sangchart. Spirituality of sick Buddhist monks. Journal of Nursing Science and Health (in Thai), Khon Kaen University, Khon Kaen, 2012; 35, 100-10.

32. Buddhadasa Bhikkhu. Nirvana here and now (in Thai). Phetpraguy, Bangkok, 2006.

33. Phra Bhramagunabhorn (PA Payutto). Buddha-Dhamma, revised and expanded Version (in Thai). $32^{\text {th }}$ ed. n.p., Bangkok, 2012.

34. Buddhadasa Bhikkhu. Heartwood of the Bodhi Tree: The Buddha's Teachings on Voidness (in Thai). Thammasapa, Bangkok, 2015.

35. Phra Dhammapitaka (PA Payutto). Mental state of nirvana. Available at: http://www.nkgen.com/22.htm, accessed July 2018. 